\title{
Implementation of a Health Gate Sterilizer Made from Herbal Disinfectants as a Tool to Prevent the Spread of the Covid-19 Virus
}

\author{
$1^{\text {st }}$ Sandey Tantra Paramitha \\ Department of Sport Science \\ Faculty of Sport and Health \\ Education \\ Universitas Pendidikan Indonesia \\ Bandung, Indonesia \\ sandeytantra18@upi.edu \\ $4^{\text {th }}$ Muhammad Gilang Ramadhan \\ Department of Doctor in Physical \\ Education \\ School of Postgraduates \\ Universitas Pendidikan Indonesia \\ Bandung, Indonesia \\ gilangramadhan16@upi.edu
}

\author{
$2^{\text {nd }}$ Komarudin Komarudin \\ Department of Sport Coaching \\ Education \\ Faculty of Sport and Health \\ Education \\ Universitas Pendidikan Indonesia \\ Bandung, Indonesia \\ komarudin_pko@upi.edu \\ $5^{\text {th }}$ Hikmat Kodrat \\ Department of Master in Physical \\ Education \\ School of Postgraduates \\ Universitas Pendidikan Indonesia \\ Bandung, Indonesia \\ hikmat11kodrat@student.upi.edu
}

\author{
$3^{\text {rd }}$ Mustika Fitri \\ Department of Sport Science \\ Faculty of Sport and Health \\ Education \\ Universitas Pendidikan Indonesia \\ Bandung, Indonesia \\ mustikafitri@upi.edu
}

\begin{abstract}
As we know that the Covid-19 virus is a problem throughout the world, many innovations have been made to prevent Covid-19. One of them is the manufacture of health gate sterilizer booths made from herbal disinfectants which are designed to sterilize the body by using a filler formulation that is harmless and beneficial for the body. Some herbs by research are considered and proven to have great antiseptic content and can be used safely for humans because of their organic nature. The purpose of this paper is to explore the design of a health gate sterilizer booth made of herbal disinfectant that is sprayed automatically, hygienically, and safe for use by the human body. One of them is an automatic device system that can be sprayed all over the body using a more perfect and simpler sterilizer chamber.
\end{abstract}

Keywords - Sterilizer Chamber, herbal disinfectant, covid-19 virus

\section{INTRODUCTION}

The explosion of a rare disease that has become a problem throughout the world, including in Indonesia, is called the corona virus pandemic (Covid-19). The World Health Organization (WHO) has declared Covid-19 a world-class pandemic which was declared on March 11, 2020 [1]. Various pharmaceutical and drug companies are working hard to find a cure for this rare disease, vaccinations have been carried out all over the world to combat the spread of the Covid-19 virus. In the current situation, WHO as a world health organization provides information and education to combat COVID-19, one of which is to always clean hands using soap or hand sanitizer that contains alcohol to combat the spread of the corona virus by touching the body directly with hands. Currently, people are washing their hands with antiseptic and using alcohol-based disinfectants.

A total of 11,324 cases of using alcohol-based hand sanitizers reported by the American Association of Potion Control Center (AAPCC) occurred in children under 12 years of age due to the COVID-19 pandemic in January-June 2020 [2]. Then the AAPCC also reported that the use of alcohol-based hand sanitizers was also used to prevent the spread of other viruses due to an increase in antimicrobial retention. However, the impact of too frequent use of alcoholbased hand sanitizers is not good for health and other environmental risks. Based on this statement, there is a need for a solution to overcome the spread of the corona virus without injuring the human body. One of the innovations currently being developed is using a health gate sterilizer made from herbal disinfectant that works automatically [3]. Seeing how it works, the use of a health gate sterilizer is more perfect than washing hands with soap, because the spraying uses an automatic chamber system where the disinfectant liquid is sprayed all over the body, so that all body surfaces can be sterilized.

The use of a health gate sterilizer made from natural resources (herbal plants) is a solution to reduce the use of alcohol which can lead to toxicity. With the Covid-19 pandemic, experts have found several plants that can play a role in replacing chemicals that are used as disinfectants as ingredients for body cleansing. 
There are several known medicinal plants and one of them is betel leaf which has anti-viral properties. For example, now there are drugs found from plants for the prevention of Covid-19 (from betel leaves and lemongrass) and are marked with a long history of use [4]. The composition of the herbal plant formulations has been tested and proven to be able to fight pathogens effectively and it also has similarities with the formulations of other body cleansers.

One way the automatic health gate sterilizer system works, with a simple and inexpensive category, is by using mild steel, thick plastic as a chamber coating, a 12 volt spray nozzle pump with 15 points, motion sensors, switch-based motion sensors on component and disinfectant materials. with a certain mixture in the jerry can. Disinfectants use herbal ingredients to be safer for the human body and are able to kill germs, bacteria and viruses. Where the way this tool works is that the spray pump will suck the antiseptic liquid on the jerry can that has been mixed with a mixture of natural ingredients, which will spray automatically when someone enters the health gate sterilizer booth, then the motion sensor will read the movement of the human inside. the chamber that is placed above the chamber [5]. After the person leaves the health gate sterilizer booth, the motion sensor will read and the automatic spraying will stop working. The real hope of making this automatic health gate sterilizer is to suppress and prevent the spread of the COVID-19 virus in public places, crowds and educational institutions such as campuses and schools. Health gate sterilizers can be placed at the entrance of public places such as campuses, markets and offices. This article aims to present the formulation of a health gate sterilizer made from herbal disinfectants as a means of preventing the spread of the covid-19 virus.

\section{METHOD}

Using Analysis Descriptive analytical research method according to is a method to obtain in-depth data, a data that contains meaning and can significantly affect the substance of the research. This means that this method presents directly the nature of the relationship between researchers and participants or objects and research subjects. This method also attempts to analysis the research subject in order to obtain in-depth data.

\section{RESEARCH RESULTS AND DISCUSSION}

Sterilization is an activity to reduce the number of bacteria or viruses that are carried by human goods or clothing, such as the Covid-19 virus which is a problem at this time. So that the most appropriate initial concept is to have the ability to design a cubicle formed from a building structure where each part has the capability to spray water in the form of a disinfectant and made from natural ingredients [6].
One of the efforts to prevent the spread of the Covid19 virus through the air which then sticks to clothes. This room is in the form of a square box with an iron frame arranged in such a way that people or visitors can enter the booth.

\section{A. Disinfectant against the corona virus}

The use of chemical disinfectants and sterilization methods is a way to eliminate microorganisms in the form of pathogens. Disinfection is a procedure or step that aims to eliminate microorganisms that are not good for the body, one of which is a pathogen[7]. While sterilization is a process that aims to eliminate all microbial activity that is not good for the body by physical or chemical methods. Materials such as ultraviolet light, plasma hydrogen peroxide gas, steam under pressure, ethylene oxide gas and liquid chemicals are the main ingredients of the sterilization process used in Healthcare facilities. In addition, cleaning is the process of removing visible particles made from organic and non-organic materials manually, such as using water and detergent [8]. Therefore, this organic and non-organic material needs to be cleaned first because it will reduce the effectiveness of the disinfection and sterilization process.

With the use of disinfectants, there are several advantages that will be obtained such as cost effectiveness, raw materials are easy to obtain, and the process does not require mechanical equipment. Chemicals that are often used in disinfectants such as chlorine, alcohol hydrogen peroxide and several other chemical compounds [9]. However, these chemicals have high toxicity. Therefore, the solution to reduce chemicals that have high toxicity is to use herbal plants as basic ingredients for disinfectants. In this case, herbal plants have been recognized as substances that provide compounds with low toxicity and high efficiency. Although herbal plants are often used as medicinal ingredients for prevention purposes, in some European countries they are used as traditional medicine for various stages of the COVID-19 disease for therapeutic purposes. Herbal medicine has been used as traditional medicine since ancient times and has significant benefits for health compared to chemical-based drugs [10].

Currently, there is no definite cure for the COVID19 virus. Therefore, solutions such as preventing the spread of the virus through droplets due to close contact and on surfaces that can be a medium for the spread of the COVID-19 virus must be prevented as early as possible. The disinfection process is the best solution as an effort to prevent the spread of COVID19 with the aim of destroying pathogenic bacteria, especially in public facilities. 


\section{B. Disinfectant Effects}

In this condition of the Covid-19 virus spreading massively to all corners of the world, it has an impact on the increased use of disinfectants as a form of preventing the spread of COVID-19. But on the other hand, this causes the use of chemicals that have a long-term adverse impact on the disinfection process, such as sodium hypochlorite, alcohol, quat and other chemical compounds [11]. These chemicals will certainly lead to the risk of diseases such as asthma, chronic lung, and eye irritation for someone who does the disinfection

The danger of chemical residues used in disinfectants is that if left on the surface of an object, it is carried into the air and eventually inhaled, after which it will result in worsening air quality in the room and will also be very risky for allergy sufferers and asthmatics. In addition, residues from these chemicals will also cause other respiratory diseases, central nervous system disorders to have an impact on other health problems, even to the point of causing cancer [12].

During the COVID-19 pandemic, there have been many opinions and misinformation circulating on social media platforms about the coronavirus. People get panicked and in anger with anxiety and fear, they take extreme measures. With concerns about the dangers of the covid-19 virus, people often act wrongly in the use of disinfectants because they think they want to always be sterile, so that the use of disinfectants is used when washing food to be consumed [13]. Such actions are certainly very dangerous and will have an impact on health problems such as permanent damage to the nervous system, permanent blindness and even coma. One of the frequently used disinfectants is a bleach solution which has a composition that can cause eye irritation or skin irritation. The material will also cause gastrointestinal toxicity because it contains caustic ingredients [14]. The use of bleach solution was reported to cause hyperchloremia, hypernatremia to injury to the lungs. This is also because chlorine bleach contains biodegradability which if not rinsed properly will also leave residues of active chemicals. In the end, it will become a medium in attracting to the adhesive for microbes that are not good. Therefore, for good sterilization and sanitation must be carried out in two steps, namely cleaning and disinfection. However, until now, there are still many uses of chemical-based disinfection, although currently herbal plant-based disinfectants are a solution to the use of chemical-based materials in the disinfection process during the COVID-19 pandemic [15]. Then disinfection with herbal ingredients is proven not only to prevent the Covid-19 virus but is also environmentally friendly because of its organic nature.

\section{Safe Precautions}

While scientists around the world are evaluating drug and vaccine candidates to treat and prevent the new coronavirus, there is currently no FDA-approved drug or vaccine available for COVID-19 infection [16]. Some researchers are always trying to find new drugs with the aim of being a potential treatment for people with COVID-19. However, it is very unfortunate that many parties are not responsible for providing wrong information to cases of fraud for the healing of COVID-19 sufferers such as herbal treatment, vitamins to colloidal silver [17]. Companies that have sold counterfeit products have been warned by the Food and Drug Administration (FDA) not to be traded again, because it is not scientifically proven that these drugs can cure COVID-19 sufferers. Because the spread of Covid-19 is transmitted through contact between infected people by coughing that produces aerosols in the air, the best solution is to prevent it by following the actions recommended by credible bodies such as the $\mathrm{CDC}, \mathrm{WHO}$ or the state health department.

The recommendation given by the Health Agency is to always clean frequently touched surfaces in public areas of the household regularly, and of course wash hands with soap regularly. Given the dangers of using disinfectants made from chemicals, during the COVID-19 pandemic, it is not recommended that disinfectants be used around non-patient areas which can cause several symptoms of respiratory disease which is also one of the consequences of exposure to the Covid-19 virus [18]. In addition, the Centers for Disease Control (CDC) provides guidelines on how to minimize the consequences of using chemical-based disinfectants by using personal protective equipment (PPE). This was done because it was based on reports that the general public did not know how to use disinfectants effectively and appropriately, thus endangering the public's health condition [19]. Environmentally friendly cleaning, namely by using a rinse water cleaner, will be more effective in eliminating the risks caused by the use of chemicalbased disinfectants. This will certainly reduce the buildup of chemical residues from the disinfectant. The Healthcare Infection Control Practices Advisory Committee (HICPAC) also explained that cleaning using rinse water and detergent is an effective procedure for environmental cleaning. During the COVID-19 pandemic, the solution to contain the spread of COVID-19 apart from the use of disinfectants is to keep your distance and wash your hands with soap.

Washing hands regularly with soap or alcohol is an important and effective way to prevent infection from the covid-19 virus, this is because the covid-19 virus will be made vulnerable and cannot infect someone. Therefore, how to wash your hands is also 
very important, such as being done for 20 seconds. However, if soap is not available, it can be replaced by alcohol which is formulated around $60-95 \%$. Even though the use of water and soap in washing hands will be more effective than using a hand sanitizer made from alcohol, because it can eliminate the number of microbes (germs), but it does not eliminate all types of germs. On the other hand, the COVID-19 pandemic has also resulted in increased use of personal protective equipment (PPE), cleaning products,

Some of the PPE that must be prioritized for medical personnel are N95 respirators, not just for ordinary people. The CDC advises ordinary citizens to just wear ordinary masks. This is because masks aim to prevent the spread of aerosols from their users to other people, also because there are some cases of infected people showing no symptoms. Therefore, it must be maintained to use masks and of course hand washing and disinfection methods must become a daily routine in preventing the spread of the covid-19 virus.

\section{Herbal Vaccine Adjuvants}

Some time ago, vaccine adjuvants made from herbal extracts have been found, which function to increase the efficiency of weak immunogenic vaccines [20]. Clinical trials are currently underway with combinations applied by veterinarians, but have not yet been tested in humans. The animals used were chickens injected with the ND vaccine to increase immunity by previously being given ginseng leaves, achyranthales, to stem saponins [21]. Safe immunostimulants and strong vaccine adjuvants made from propolis can induce an earlier and longer-lasting immune response. Propolis is also used in China as a traditional medicine in enhancing humoral and cellular responses. It also exhibits new adjuvant properties of saponins, derived from Crocus Sativus saffron.[22].

Saponins are adjuvants that can increase humoral immunity and T cells. Saponins derived from ginseng stems and their combination with selenium $(\mathrm{Se})$ can increase the specific antibody for Newcastle Disease Virus (NDV) and Infectious Bronchitis Virus (IBV). In addition, this saponin has been successful in its use in immunostimulant complexes between saponins and viral glycoproteins as animal vaccines and has also been successful for treatment in humans. This is very good news in the use of disinfectants to replace chemicals into herbal plant materials.

\section{E. Disinfectant Betel Leaf}

Betel leaf is a plant that contains antiseptic substances and can kill bacteria and fungi and has antioxidant power [23]. This betel plant is widely planted around the environment so it is easy to obtain.
However, people do not know the health benefits, betel leaf contains essential oils which have germicidal properties and contain compounds that inhibit the growth of bacteria. This betel leaf contains a lot of phenolic derivatives. The betel leaf is used for medicinal purposes, the betel leaf has a heart-like shape with a pointed tip, has a rough texture to the touch, and is aromatic. The leaves are used as anticancer, astringent, and also antiseptic.

With the development of COVID-19, which is increasing, the demand for hand sanitizers is increasing. Hand sanitizer is very much needed by the community as a hand sanitizer [24]. Meanwhile, the number of hand sanitizer supplies is increasing, so the demand and supply numbers are not comparable. This makes hand sanitizers expensive. To overcome the high cost of hand sanitizers, innovations in making hand sanitizers can use natural ingredients, namely betel leaves. Betel leaf availability is abundant around, so the price of the product becomes cheap. Betel leaf hand sanitizer contains bioactive compounds that can inhibit the growth or kill microorganisms. The manufacture of green betel leaf extract hand sanitizer gel refers to the formula for making hand sanitizers carried out by Sari (2006) and Rahman (2021). Based on the results of research by Sari (2006) that the gel preparation with $25 \%$ betel leaf extract was able to eliminate all microorganisms. Meanwhile, according to Rahman (2012) that the best formulation of hand sanitizer gel in terms of the area of the bacterial inhibition zone, gel viscosity, gel deployment, and $\mathrm{pH}$, which contains $0.75 \% \mathrm{CMC}$ as much as $0.25 \%$ chitosan. hand hygiene, can also be used as a business opportunity for the community in improving the economy by utilizing betel leaf plants. Betel leaf has many benefits, one of which is the manufacture of hand sanitizer. With the manufacture of betel leaf hand sanitizer, it is hoped that this is one of the early prevention efforts of the corona virus. This activity is a form of education to prevent the spread of the corona virus (covid-19) in the application of health protocols. and $\mathrm{Ph}$, which contains $0.75 \%$ chitosan, $0.25 \%$ CMC. The selection of this betel leaf hand sanitizer is to maintain hand hygiene, it can also be used as a business opportunity for the community in improving the economy by utilizing betel leaf plants. Betel leaf has many benefits, one of which is the manufacture of hand sanitizer. With the manufacture of betel leaf hand sanitizer, it is hoped that this is one of the early prevention efforts of the corona virus. This activity is a form of education to prevent the spread of the corona virus (covid-19) in the application of health protocols. and $\mathrm{Ph}$, which contains $0.75 \%$ chitosan, $0.25 \%$ CMC.

The selection of this betel leaf hand sanitizer is to maintain hand hygiene, it can also be used as a 
business opportunity for the community in improving the economy by utilizing betel leaf plants. Betel leaf has many benefits, one of which is the manufacture of hand sanitizer. With the manufacture of betel leaf hand sanitizer, it is hoped that this is one of the early prevention efforts of the corona virus. This activity is a form of education to prevent the spread of the corona virus (covid-19) in the application of health protocols. can also be used as a business opportunity for the community in improving the economy by utilizing betel leaf plants. Betel leaf has many benefits, one of which is the manufacture of hand sanitizer. By making this betel leaf hand sanitizer, it is hoped that it will be one of the early prevention efforts for the corona virus. This activity is a form of education to prevent the spread of the corona virus (covid-19) in the application of health protocols. can also be used as a business opportunity for the community in improving the economy by utilizing betel leaf plants. Betel leaf has many benefits, one of which is the manufacture of hand sanitizer. With the manufacture of betel leaf hand sanitizer, it is hoped that this is one of the early prevention efforts of the corona virus. This activity is a form of education to prevent the spread of the corona virus (covid-19) in the application of health protocols.

\section{CONCLUSION}

The COVID-19 virus has become a global threat. It is clear that every day the number of cases of COVID-19 infection continues to increase globally. On the other hand, the solution with the development of a vaccine and also a harmless disinfectant is still in the process of clinical trials, which of course will take time. This resulted in an increase in the level of public anxiety because they saw the potential for an increase in the massive spread of the COVID-19 virus, and which allowed the inappropriate use of chemicalbased disinfectants to have a negative impact on human health and the environment. Health gate sterilizer made from herbal disinfectant as a tool to prevent the spread of the covid-19 virus is designed with design methods and concepts, the ideal design is obtained to be applied in crowded areas such as campus institutions, schools and places of worship. With materials that are easier to find on the market and simplified manufacturing costs, it becomes a superior product and a solution to deal with the spread of the corona virus.

\section{REFERENCES}

[1] Organización Mundial de la Salud, "Guatemala: WHO Coronavirus Disease (COVID-19) Dashboard | WHO Coronavirus Disease (COVID-19) Dashboard," Who.int. 2021.

[2] S. Nyayakar, S. D. Sundar Singh, M. Christan, and M. Kurian Joseph, "A REVIEW ON ALCOHOL BASED HAND SANITIZER (ABHS) POISONING DURING COVID-19 PANDEMIC AMONG YOUNG CHILDREN," PARIPEX INDIAN J. Res., 2021.

[3] N. K. Rai, A. Ashok, and B. R. Akondi, "Consequences of chemical impact of disinfectants: safe preventive measures against COVID-19," Critical Reviews in Toxicology. 2020.

[4] H. Soni, S. Sharma, and J. K. Malik, "Synergistic prophylaxis on COVID-19 by nature golden heart (Piper betle) \& Swarna Bhasma," Asian J. Res. Dermatological Sci., 2020.

[5] A. Grigore, D. Cord, C. Tanase, and R. Albulescu, "Herbal medicine, a reliable support in COVID therapy," Journal of Immunoassay and Immunochemistry. 2020.

[6] S. J. Kim et al., "Application of chitosan as a natural disinfectant against porcine epidemic diarrhoea virus," Acta Vet. Hung., 2021.

[7] S. M. Sharafi, K. Ebrahimpour, and A. Nafez, "Environmental disinfection against COVID-19 in different areas of health care facilities: A review," Reviews on Environmental Health. 2021.

[8] S. M. El-Megharbel, M. Alsawat, F. A. Al-Salmi, and R. Z. Hamza, "Utilizing of (Zinc oxide nano-spray) for disinfection against 'sars-cov-2' and testing its biological effectiveness on some biochemical parameters during (covid-19 pandemic) - "zno nanoparticles have antiviral activity against (sars-cov2),", Coatings, 2021.

[9] H. Choi et al., "Classical and alternative disinfection

strategies to control the COVID-19 virus in healthcare facilities: a review," Environmental Chemistry Letters. 2021.

[10] Y. Li et al., "Traditional Chinese herbal medicine for treating novel coronavirus (COVID-19) pneumonia: Protocol for a systematic review and meta-Analysis," Syst. Rev., 2020.

[11] M. Achak, S. Alaoui Bakri, Y. Chhiti, F. E. M'hamdi Alaoui, N. Barka, and W. Boumya, "SARS-CoV-2 in hospital wastewater during outbreak of COVID-19: A review on detection, survival and disinfection technologies," Science of the Total Environment. 2021.

[12] J. M. Garrido-Molina et al., "Disinfection of gloved hands during the Coronavirus outbreak (COVID2019).," J. Hosp. Infect., 2020.

[13] L. H. Chang and D. Noordermeer, "Of Dots and Stripes: The Morse Code of Micro-C Reveals the Ultrastructure of Transcriptional and Architectural Mammalian 3D Genome Organization," Mol. Cell, 2020.

[14] A. Tripathi, S. Mantell, and J. L. Le, "Chemomechanical modeling of static fatigue of high density polyethylene in bleach solution," Int. J. Solids Struct., 2021.

[15] M. C. Noushad, K. Ashraf, and M. P. Suneetha, "Antibacterial efficacy of muringa seed extract and potato peel extract against enterococcus faecalis," Contemp. Clin. Dent., 2020.

[16] D. Lu, L. Sang, S. Du, T. Li, Y. Chang, and X. A Yang, "Asymptomatic COVID-19 infection in late pregnancy indicated no vertical transmission," J. Med. Virol., 2020.

[17] M. M. Donma and O. Donma, "The effects of allium sativum on immunity within the scope of COVID-19 infection," Med. Hypotheses, 2020.

[18] M. H. Al-Sayah, "Chemical disinfectants of COVID- 
19: An overview," Journal of Water and Health. 2020.

[19] Å. Babić, R. Turk, and J. MacAn, "Toxicological aspects of increased use of surface and hand disinfectants in Croatia during the COVID-19 pandemic: A preliminary report," Arh. Hig. Rada Toksikol., 2020.

[20] Y. C. Song et al., "A Potential Herbal Adjuvant Combined With a Peptide-Based Vaccine Acts Against HPV-Related Tumors Through Enhancing Effector and Memory T-Cell Immune Responses," Front. Immunol., 2020.

[21] K. Liu et al., "Polysaccharide PCP-I isolated from Poria cocos enhances the immunogenicity and protection of an anthrax protective antigen-based vaccine," Hum. Vaccines Immunother., 2020.

[22] NCT04452799, "Hesperidin and Diosmin for Treatment of COVID-19," https://clinicaltrials.gov/show/NCT04452799, 2020.

[23] Melpiany, B. Bachtiar, S. A. Paembonan, and S. H. Larekeng, "The effect of betel leaves as the soak solution for Bitti (Vitex cofassus) seeds germination," in IOP Conference Series: Earth and Environmental Science, 2020

[24] S.- Nugrahini, "The Discoloration of Heat Cured Resin Acrylic Base After Immersed in Disinfectant Solution," SONDE (Sound Dent., 2020. 